\title{
Moving from clinician-defined to patient-reported outcome measures for survivors of high-grade glioma
}

This article was published in the following Dove Press journal: Patient Related Outcome Measures

\author{
Lena Rosenlund ${ }^{1,2}$ \\ Eskil Degsell 1,3,4 \\ Asgeir Store Jakola ${ }^{5-7}$ \\ 'Regional Cancer Centre Stockholm, \\ Stockholm, Sweden; ${ }^{2}$ Institute of Health \\ and Care Sciences, Sahlgrenska Academy, \\ Gothenburg, Sweden; ${ }^{3}$ Malignant Brain \\ Tumor Pathway, Quality and Patient \\ Safety Department, Karolinska University \\ Hospital, Stockholm, Sweden; ${ }^{4}$ The \\ Swedish Brain Tumor Association, \\ Stockholm, Sweden; ${ }^{5}$ Department of \\ Clinical Neurosciences, Institute of \\ Physiology and Neuroscience, \\ Sahlgrenska Academy, Gothenburg, \\ Sweden; ${ }^{6}$ Department of Neurosurgery, \\ Sahlgrenska University Hospital, \\ Gothenburg, Sweden; ${ }^{7}$ Department of \\ Neurosurgery, St. Olavs Hospital, \\ Trondheim, Norway
}

Background: Persons with high-grade glioma face both neurological and cancer-related symptoms from the tumor itself and its treatment affecting their daily lives. Survival alone is not an adequate outcome, the quality of the survivorship experience needs to be regarded with equal importance. Patient-reported outcome (PRO) measures can be used to evaluate treatment effects and symptom management interventions.

Purpose: The aim of this review was to identify the use, challenges, and potential of PRO measures in survivors of high-grade glioma.

Methods: A narrative expert opinion review was performed on the subject. In addition to our own experiences we searched PubMed, Cumulative Index to Nursing and Allied Health Literature, the Cochrane Library, and PsycINFO for brain tumor-specific PRO measures used in the population of adult patients with high-grade glioma, both original articles and reviews were included.

Results: There are several PRO measures that have been validated for patients with primary brain tumors including high-grade glioma. PRO measures are used both in clinical trials to evaluate the effect of treatment on health-related quality of life, and in daily clinical practice for holistic needs assessment and symptom management. Common PRO measures used for patients with high-grade glioma are European Organization for Research and Treatment of Cancer general instrument for patients with cancer together with brain tumor module, Functional Assessment of Cancer Therapy-Brain, and MD Anderson Symptom Inventory for Brain Tumor. Neurologic and cognitive disorders often occur in patients with high-grade glioma, which affects patients' ability to self-report over time, making it more challenging in this population. PRO as a primary outcome seems underutilized.

Conclusion: For clinical research, PRO measures need to be used together with other clinical outcome measures rather than replacing traditional outcome measures. Moving to more use of PRO measures in survivorship care has potential to improve patient-caregiverhealthcare team communication, symptom management, and quality of care. Implementing PROs in survivorship care should also involve caregivers and a response based on the results.

Keywords: high-grade glioma, brain tumor, patient-reported outcome measures, symptom management

\section{Introduction}

Correspondence: Lena Rosenlund University of Gothenburg, Regional Cancer Centre Stockholm, Box 6909, Stockholm 10239 , Sweden

Tel +4673668 I89I

Email lena.rosenlund@gu.se
Gliomas are the most common primary brain tumor in adults. They are classified into different subgroups and graded according to WHO tumor grade (ranging from I-IV) where higher grade means more malignant tumor. ${ }^{1}$ High-grade gliomas, WHO grade 
III-IV, (ie, anaplastic astrocytoma, anaplastic oligodendroglioma, and glioblastoma) are considered incurable and there are limited numbers of long-term survivors. Acute or subacute neurologic symptoms such as headaches, seizures, neurocognitive dysfunction, and motor deficit, often lead to diagnosis and impact patients from the time of diagnosis. ${ }^{2}$ Treatment of high-grade glioma is multimodal, incorporating surgery, radiotherapy, and/or chemotherapy. ${ }^{3-7}$ Although treatment aims to prolong life, these modalities may have implications in terms of both short- and long-term symptoms and health-related quality of life (HRQoL). ${ }^{8}$

Traditional outcome measures used for patients with cancer are tumor size and response to treatment, overall survival, and prolonging patients' lives with stable disease, so-called progression-free survival. Today, most clinical trials also include patient-centered outcomes, or clinical outcome assessment (COA) tools, to evaluate the effect of treatments on patient function and impact on HRQoL. According to The US Food and Drug Administration (FDA), there are four different types of COA measures; patient-reported outcomes (PROs), clinician-reported outcomes (ClinROs), observerreported outcomes (ObsROs), and performance outcomes (PerfOs), Table 1. PROs are defined as any aspect of a patient's health condition reported directly by the patient without interpretation of the patient's response by a physician or anyone else. PROs can provide insight into subjective concepts only known to the patient, like HRQoL and experience living with the disease. ${ }^{9,10}$ ClinRo assessments are conducted and reported by health care professionals, for example, assessment of neurological function. ObsRO measures report about the patient's health condition from someone other than the patient or the health care professionals, usually a family member. Observer or proxy reports can be used when a patient cannot self-report, for example, due to cognitive or linguistic problems. PerfO measures are usually administered by a health care professional and performed by the patient, for example, a neurocognitive test. ${ }^{9}$

Data available from qualitative studies about the experience of patients with high-grade glioma indicate a high symptom burden with complex and dynamic supportive care needs also affecting family members, friends, and caregivers sharing the survivorship experience with the patient. $^{11-15}$ Survivorship care and survivorship care plans are needed and are being implemented in neurooncology. ${ }^{16,17}$ According to the National Coalition for Cancer Survivorship and the NCI Office of Cancer "An individual considered a cancer survivor from the time of diagnosis, and throughout the balance of his or her life."

Table I Different patient-centered outcome measures

\begin{tabular}{|c|c|c|}
\hline \multicolumn{3}{|c|}{ Patient-centered outcome measures } \\
\hline Clinical outcome assessment & Definition & Example \\
\hline PRO measures & $\begin{array}{l}\text { Patient-reported outcome, patient's self-report of } \\
\text { symptoms, function or health-related quality of life }\end{array}$ & $\begin{array}{l}\text { Health-related quality of life: EORTC-QLQ-C30 and } \\
\text { BN20, FACT-Br } \\
\text { Symptom assessment: MDASI-BT }\end{array}$ \\
\hline PerfO measures & $\begin{array}{l}\text { Performance outcome, testing of patient's function } \\
\text { by a professional }\end{array}$ & $\begin{array}{l}\text { Neurocognitive function: for example The Montreal } \\
\text { Cognitive Assessment (MMSA) } \\
\text { Function/Activity limitations, BADL: ex. Barthel index } \\
\text { (BI) }\end{array}$ \\
\hline ClinRO measures & $\begin{array}{l}\text { Clinician-reported outcomes, assessments were a } \\
\text { clinician applies professional expertise to judge and } \\
\text { interpret their observations of a patient's health or } \\
\text { function }\end{array}$ & $\begin{array}{l}\text { Performance status: ECOG/WHO performance } \\
\text { status, KPS scale, } \\
\text { Neurologic assessment: NANO scale }\end{array}$ \\
\hline ObsRO measures & Observer-reported outcomes & $\begin{array}{l}\text { Observations reported by someone else who knows } \\
\text { the patient, usually a family member, for example, } \\
\text { observations about patients' behavior or function in } \\
\text { daily life }\end{array}$ \\
\hline
\end{tabular}

Abbreviations: EORTC QLQ-C30, European Organization for Research and Treatment of Cancer general instrument for patients with cancer; EORTC BN20, European Organization for Research and Treatment of Cancer brain tumor module; FACT-Br, Functional Assessment of Cancer Therapy-Brain; IADL, Instrumental activities in daily life; MDASI-BT, MD Anderson Symptom Inventory for Brain Tumor; NANO, Neurologic Assessment in Neuro-Oncology. 
Important components identified in survivorship care are surveillance of new or recurrent cancers, coordination of care, and support for consequences of cancer and treatment. ${ }^{18}$ Symptom management is one of the key components and includes identifying, preventing or treating the symptoms of the disease, side effects caused by treatment, and psychological, social or spiritual problems related to the disease or the treatment. ${ }^{19}$ Symptom management strategies can incorporate preventive interventions, patient and family self-management methods, and prescribed interventions to treat symptoms. ${ }^{20}$

In this review, we aimed to describe the current use of PROs in survivors and survivorship care of high-grade glioma. We highlighted the potential and challenges of PRO in this group of patients.

\section{Methods}

For this narrative expert review we searched the e-resources PubMed, the Cochrane Library, Cumulative Index to Nursing and Allied Health Literature (CINAHL), and PsycINFO for PROs used for adult patients with highgrade glioma. Inclusion criteria were original articles and reviews in English language reporting use of PROs in clinical trials or clinical practice in adult patients with high-grade glioma. The search strategy consisted of a combination of terms for (High-grade gliomas) OR (Glioma) OR (Brain neoplasms) OR (Brain tumors) AND (Patient Reported Outcome Measures) OR (Patient Outcome Assessment) OR (Self-Assessment). Additional articles were identified through previous topical reviews. PRO measures not specific for primary brain tumors, PROs for onedimensional specific symptoms or studies that included both patient and caregiver assessments were excluded.

\section{Results}

There are several PRO measures specifically validated for patients with brain tumors including high-grade glioma, as seen in Table 2. PROs are used both in clinical trials to evaluate the effect of treatment on HRQoL and in daily clinical care for needs assessment and symptom management.

\section{PRO measures in clinical trials for patients with high-grade glioma}

PROs, usually HRQoL, are used in clinical trials to assess the impact of new therapeutic strategies on the patient. HRQoL can also be an important second primary endpoint in trials where the treatment has no effect on overall survival, but improvement in HRQoL is observed. ${ }^{21} \mathrm{HRQoL}$ is defined as a multidimensional concept, covering physical, psychological, and social dimensions as well as symptoms induced by the disease and its treatment. ${ }^{22}$ This is especially important in high-grade glioma patients, where improving survival has been shown to be extraordinarily difficult and maintenance or improvement of neurologic function and HRQoL are as important as prolonged survival. ${ }^{9,23,24}$ PRO measures used in clinical trials for patients with high-grade glioma are HRQoL and symptom burden. ${ }^{25}$ In a systematic review by Dirven et al, 2014, they looked at the level of PRO measures reported and the methodological quality of the PRO reporting in randomized controlled trials (RCTs) of primary malignant brain tumors. In 13 out of 14 of the RCTs identified (2004-2012) the Functional Assessment of Cancer Therapy-Brain (FACT$\mathrm{Br}^{26-29}$ or the European Organization for Research and Treatment of Cancer general instrument for patients with cancer (EORTC QLQ-C30) 30-38 $^{38}$ was to measure HRQoL. ${ }^{39}$ Several challenges using PRO measures in clinical trials have been reported, including concerns regarding the methodological quality of the reporting of PRO measures. PRO measures that should be used in clinical decisions need to be collected, analyzed, and interpreted correctly. Using the International Society for Quality of Life Research checklist for reporting PRO measures, ${ }^{40,41}$ only two of the RCTs provided high-quality PRO evidence. ${ }^{6,36,39}$ Since then, the use and reporting of PROs in clinical trials have been discussed and are now more frequently reported in a separate paper and according to guidelines or checklists. ${ }^{42,43}$ Other limitations to be aware of using PRO measures in neuro-oncology have been described and include missing data, patient's ability to selfreport, selection bias, timing of the assessment, and response shift. ${ }^{44,45}$ Common reasons of missing data are often administration failure, high symptom burden or progression of disease. Electronic data capture may facilitate data collection and reduce missing data due to administration failure. Patients with high-grade glioma often also suffer from neurologic and cognitive disorders which also affect patients' ability to selfreport, resulting in unreliable or missing data. Studies that have explored the use of caregivers as proxy when patients are not able to self-report have mixed results. ${ }^{9,45,46}$ For patients with high-grade glioma and proxy ratings, there are studies which used EORTC QLQ-C30, ${ }^{47,48}$ Fact-Br, ${ }^{49-51}$ and MD Anderson Symptom Inventory for Brain Tumor (MDASIBT) ${ }^{52,53}$ showing fair-to-good congruence between patients and their proxies, but in clinical trials, reporting of PROs usually ends when patients are not able to self-report. 
Table 2 Patient-reported outcomes used in neuro-oncology

\begin{tabular}{|c|c|c|c|c|}
\hline Tool & $\begin{array}{l}\text { Number } \\
\text { of items }\end{array}$ & Purpose & Domains & Reference \\
\hline \multicolumn{5}{|c|}{ Health-related quality of life } \\
\hline EORTC QLQ-C30 & 30 & $\begin{array}{l}\text { Health-related quality of life, } \\
\text { generic instrument for patients } \\
\text { with cancer }\end{array}$ & $\begin{array}{l}\text { Five functional scales (physical, role, emotional, cognitive and } \\
\text { social functioning), three symptom scales (fatigue, pain, and } \\
\text { nausea/vomiting), six single items (dyspnea, insomnia, appetite } \\
\text { loss, constipation, diarrhea, and financial impact) and a two- } \\
\text { item scale for global health and overall quality of life. } \\
\text { Recall period: last week }\end{array}$ & 91 \\
\hline EORTC-QLQ-BN20 & 20 & Brain cancer module & $\begin{array}{l}\text { BN20 four multi-item scales (future uncertainty, visual disorder, } \\
\text { motor dysfunction, and communication deficit) and } \\
\text { seven single-item symptom scales (headaches, seizures, } \\
\text { drowsiness, hair loss, itchy skin, leg weakness, and bladder } \\
\text { control) } \\
\text { Recall period: last week }\end{array}$ & 92 \\
\hline FACT-G & 27 & $\begin{array}{l}\text { Health-related quality of life, } \\
\text { generic instrument for patients } \\
\text { with cancer }\end{array}$ & $\begin{array}{l}\text { Five domains (functional, physical, social, family, and } \\
\text { emotional well-being) }\end{array}$ & 93,94 \\
\hline FACT-Br & 23 & Brain cancer module & 23 items brain tumor-specific symptoms & 95 \\
\hline \multicolumn{5}{|c|}{ Symptom assessment tools } \\
\hline MDASI-BT & $\begin{array}{l}22 \\
6\end{array}$ & $\begin{array}{l}\text { Cancer- and brain tumor } \\
\text { specific symptoms. } \\
\text { Symptom severity and } \\
\text { interference in daily life }\end{array}$ & $\begin{array}{l}22 \text { items in six domains (general, gastrointestinal, } \\
\text { constitutional, neurologic deficit, cognitive, and affective) } \\
\text { Interference in daily life, (activity and mood) } \\
\text { Recall period: } 24 \text { hours }\end{array}$ & $67,93,94,96$ \\
\hline $\mathrm{NFBrSI}-24$ & 24 & $\begin{array}{l}\text { Symptom assessment/ } \\
\text { Symptom index for patients } \\
\text { with advanced brain tumors }\end{array}$ & $\begin{array}{l}24 \text { items, where } 21 \text { out of } 24 \text { items are included in FACT-Br } \\
\text { three subscales (disease-related symptoms, treatment side } \\
\text { effects and function/well-being) } \\
\text { Recall period: } 7 \text { days }\end{array}$ & 71 \\
\hline \multicolumn{5}{|c|}{ Holistic and supportive care needs assessment } \\
\hline Brain $\mathrm{PCl}$ & $\begin{array}{l}48 \\
10 \\
4\end{array}$ & Holistic needs assessment & $\begin{array}{l}\text { Section I. } 48 \text { items for practical, family, emotional, spiritual } \\
\text { and physical issues } \\
\text { Section 2. } 10 \text { items, referral requests } \\
\text { Section } 3.4 \text { fields for writing questions } \\
\text { Recall period: prior to visits }\end{array}$ & 72 \\
\hline SCNS34-BS & $\begin{array}{l}34 \\
16\end{array}$ & Supportive care needs & $\begin{array}{l}34 \text { items (psychologic, health system and information, } \\
\text { physical and daily living, patient care and support, sexuality) } \\
16 \text { brain tumor-specific items } \\
\text { Recall period: last months }\end{array}$ & 97,98 \\
\hline
\end{tabular}

Abbreviations: EORTC QLQ-C30, European Organization for Research and Treatment of Cancer general instrument for patients with cancer; EORTC BN20, European Organization for Research and Treatment of Cancer brain tumor module; FACT-G, Functional Assessment of Cancer Therapy-General; FACT-Br, Functional Assessment of Cancer Therapy-Brain; MDASI-BT, MD Anderson Symptom Inventory for Brain Tumor; NFBrSI-24, National Comprehensive Cancer Network \& Functional Assessment of Cancer Therapy Brain Symptom Index; PCI, Patient Concern Inventory; SCNS34-BS, Supportive Care Needs Survey 34 plus brain subscale.

\section{PRO measures in clinical practice}

There is a growing interest in using PROs to improve individual patient care, both from health care professionals and patients themselves. There are hospitals implementing electronic PROs into routine oncology practice for symptom assessment and management. ${ }^{54}$ PRO measures have been advocated as an effective way to improve patient-provider communication, symptom control, self-management, and increase patient satisfaction. ${ }^{55}$ In two randomized trials in patients with other types of cancers (not brain tumors), 
patients receiving chemotherapy were randomly assigned to either electronic patient-reported symptom monitoring (and a routine to respond to patients' results when needed) or usual/ traditional care. ${ }^{56,57}$ The group of patients assigned to electronic patient-reported symptom monitoring had better $\mathrm{HRQoL}^{56}$ and in one trial even increased survival compared to the group with usual care. ${ }^{57}$ However, to our knowledge, published work of this set-up in patients with high-grade glioma is lacking. Challenges of integrating PROs in clinical practice are many, among them engaging health care professionals to implement PROs into existing clinical workflows ${ }^{58}$ and selecting PRO measures that are meaningful to the patients and have adequate psychometric properties. ${ }^{59}$ When implementing PROs in clinical practice, it is also important to aid both patients and health care professionals, to visualize results so they can be easily interpreted and so that they can act on the results. ${ }^{60-62}$ For patients with highgrade glioma, we found specific tools for symptom assessment and holistic needs assessment (HNA) being used in clinical practice, as seen in Table 2.

Symptom assessment and management is an important part of survivorship care. Patients with high-grade glioma experience both cancer-related symptoms like fatigue and future uncertainty, and progressive neurologic symptoms caused by the tumor itself and treatment. ${ }^{2,8}$ Therefore, generic PRO measures cannot always be used in this population to detect symptoms or needs. In the Conceptual framework for survivorship care for neuro-oncology described by Leeper and Milbury, they present potential PROs to use in neuro-oncology survivorship care; HRQoL, fatigue, mood, functional status, cognitive status, seizure control, headache, and pain. ${ }^{16}$

HRQoL instruments such as EORTC QLQ-C30 are also used in clinical practice ${ }^{63,64}$ and the EORTC QLG has developed a manual for the use of EORTC instruments in clinical practice. ${ }^{65}$ King et al, 2016, examined the use and impact of HRQoL assessment tools in clinical cancer care settings, but did not find any studies exclusively in brain cancer patients. ${ }^{66}$ In addition to those PRO instruments used to measure HRQoL, there are other instruments for measuring symptoms and symptom burden in patients with brain tumors, the MDASI-BT ${ }^{25,67}$ and the National Comprehensive Cancer Network \& Functional Assessment of Cancer Therapy Brain Symptom Index (NFBrSI-24), as seen in Table 2. The MDASI-BT was developed to cover both cancer-related and neurologic symptoms in patients with primary brain tumors and is used in both clinical practice and trials to identify symptoms, symptom severity, impact on patients' life, and to evaluate symptom management interventions. ${ }^{2,25,67-70}$ The NFBrSI-24 is a more recently developed tool to assess symptoms in patients with advanced brain tumors. ${ }^{71}$

The aim with HNA is to provide a more holistic view of the complex needs of patients and to enhance communication between the patient, caregivers, and health care providers. There are a number of clinical tools to support HNA in cancer care, for example, the National Comprehensive Cancer Network (NCCN) Distress Thermometer. HNA tools are often designed as a checklist and are easy for the patient to complete before consultations. This process can help patients (and caregivers) to describe their situation and to remember to ask questions. It can also help health care professionals to focus on the patient's agenda. ${ }^{72,73}$ The NCCN Distress Thermometer has been used successfully to detect distress in patients with primary brain tumors including high-grade glioma. ${ }^{74,75}$ But generic cancer HNA tools may need to be adapted to also capture the different neurological symptoms and concerns occurring in patients with high-grade glioma. ${ }^{72}$ A recent systematic review evaluated existing brain-specific PRO measures used in adult brain tumor patients in clinical settings to investigate the potential of these for HNA. They found four clinical tools: the Brain Patient Concern Inventory (Brain PCI), ${ }^{72}$ the MDASI-BT, ${ }^{67,76}$ the NFbrSI-24, ${ }^{71}$ and the Supportive Care Needs Survey 34 plus brain subscale (SCNS34-BS), as seen in Table 2. The Brain PCI and SCNS34-BS were designed for clinical use and HNA prior to visits but needed psychometric testing, whereas the MDASI-BT and NFbrSI24 are psychometric-tested symptom assessment tools but would need further development to be used for HNA. ${ }^{77}$

\section{Discussion}

The aim of this review was to identify the current use of PRO measures in survivors of high-grade glioma, and to reflect on potential and challenges of different outcome measures. We observed that there is a movement toward more use of PROs in cancer patients including patients with high-grade glioma. However, for patients with highgrade glioma, there is a relative lack of data concerning long-term PROs, use of PROs in clinical practice, interventions to improve PROs, and even patient satisfaction where PROs are used. There is a risk for "questionnaire fatigue" if PROs are increasingly used and not acted upon.

Traditional outcomes in patients with high-grade glioma are surprisingly complex and have their shortcomings. For example, radiological response assessment has shown both pseudo-progression and pseudo-response 
depending on treatment. ${ }^{78,79}$ For this reason, different outcomes are needed in combination to get a reasonable picture of the disease status of a patient. To improve the response assessment in neuro-oncology, the "Response Assessment in Neuro-Oncology" ("RANO") working group has established criteria that can be used for brain tumors. ${ }^{80}$ There is a movement toward clinical trials where different COAs are used together to evaluate net clinical effect, with both subjective and objective measures. For example, in RTOG 0525, a combination of neurocognitive tests, HRQoL (EORTC QLQ-C30 and BN20), and symptoms (MDASI-BT) was used. ${ }^{81}$ Recently, a ClinRO assessment tool for neurologic function among neuro-oncology patients was developed, The Neurologic Assessment in Neuro-Oncology (NANO) scale. The NANO scale was designed to be combined with radiographic assessments and other COAs like PRO measures and neurocognitive tests, to provide an overall assessment of outcome for neuro-oncology patients in clinical trials and in daily practice. $^{82}$

Commonly used PRO measures for patients with highgrade glioma are EORTC QLQ-C30, ${ }^{47,48}$ Fact-Br, ${ }^{4-51}$ and MDASI-BT. 52,53 The "Response Assessment in NeuroOncology-Patient-Reported Outcome" ("RANO-PRO”) working group provides guidance on the use of PRO and will develop existing and new PRO measures for adult patients with brain tumors, where needed. ${ }^{9}$ The RANOPRO group and the EORTC quality of life group are developing a self- or observer-reported instrument to measure instrumental activities in daily life (IADL), in brain tumor patients. The EORTC IADL for patients with brain tumors will include complex activities in a patient's daily life like preparing food, ability to handle finances, shopping, and housekeeping. ${ }^{83,84}$ There is also ongoing work to update the EORTC brain cancer module BN20. The brain cancer module was developed more than 20 years ago and since then treatments have changed and patients may now experience symptoms not captured by the current questionnaire (https://qol.eortc.org/questionnaire/bn20-update/).

Where clinical trials are designed to follow patients' HRQoL until progression or recurrence, there is a risk that long-term side effects from treatment might be missed. There are PRO measures which capture specific issues in cancer survivors, but not used in patients with high-grade glioma that we know of. The EORTC quality of life group is developing a PRO instrument to capture HRQoL issues relevant to disease-free survivors of cancer, EORTC QLQ cancer survivorship questionnaire. They describe a "cancer survivor" as any person who has been diagnosed with cancer who has completed treatment with curative intent (with the exception of maintenance treatment) and is disease-free (no evidence of active cancer). This definition may not suit patients with high-grade glioma but lowgrade glioma patients were included in the study. ${ }^{85}$

To improve measurement precision and relevance to patients, PRO measures should ideally be adapted to the individual patient while retaining direct comparability of scores across patients. This is achievable using item banks and computerized adaptive tests (CATs). The EORTC quality of life group has developed a CAT item bank for the functional domains and symptoms of the EORTC QLQ-C30. The EORTC CAT Core will be a more precise and flexible measurement system than the EORTC QLQC30. ${ }^{86}$ Another item bank is the National Institutes of Health Patient Reported Outcomes Measurement Information System (PROMIS). PROMIS was developed for the general population with multiple chronic health conditions and has been used to measure common cancer symptoms in routine oncology outpatient care. ${ }^{87} \mathrm{~A}$ recent study used the item banks PROMIS and The Quality of Life in Neurological Disorders (Neuro-QOL) to evaluate low- and high-grade glioma patients' perspective on functional domain affecting HRQoL. ${ }^{88}$

However, there are limitations to the use of PRO measures that should be acknowledged. Due to consequences of neurologic and cognitive disorders often occurring in patients with high-grade glioma the transition to "PROs only" in patients with high-grade glioma may be problematic. In addition, since the more traditional outcome measures are extraordinarily important in interventional studies, the field of high-grade glioma is not ready for a move from clinician-reported outcome measures to PRO measures. The situation would perhaps be different if longevity was the rule due to effective treatment. We acknowledge that trained health care professionals can sometimes identify symptoms not known to either the patient themselves or caregivers, but under-reporting of symptoms by clinicians may be a more common scenario. ${ }^{89}$ On the other hand, in observational studies and in daily clinical practice, PROs and observer or proxy reports from caregiver are crucial. We also need to know more about how to involve close caregivers as proxies or observers. Studies using proxy reports often look at caregiver and patient congruence for HRQoL ratings, but we know there might be a point where patients' and caregivers' consensus decreases. One way is therefore to obtain proxy ratings alongside a patient's own self-report until the 
patient can no longer report him- or herself and then consider using patient by proxy ratings. ${ }^{90}$ Caregivers need instructions on how they can help the patient respond or how they can respond as a proxy or an observer. Maybe we need a PRO proxy version with additional information for caregivers. Another way is to use more observer or objective measures for caregivers, like the IADL.

There are clear benefits of moving toward more active use of PRO measures in clinical practice. We think PRO measures better capture symptoms related to quality of survival as experienced by patients, and assessment may facilitate communication between parties. In addition, active involvement of patients and caregivers is likely to facilitate learning, empowerment, and self-management in addition to communication. This is important on individual level, but also, aggregated research data are important to better guide direction for future symptom management and research. Even though item banks and CATs may choose questions more relevant to the patient, what helps the patient is presumably not the measurement itself but how we understand and respond to the patients' results. If we want to create better health outcomes it is important that we understand the meaning of the symptoms for the individual. The most common symptom might not always be the most severe. Complexity of the cause of symptoms and distress in patients with high-grade glioma also make it difficult to evaluate supportive and treatment effects. One obstacle is the lack of evidence to support many symptombased interventions, making it challenging for health care professionals to provide recommendations. ${ }^{20}$ Still, to see a PRO measure as primary outcome in clinical trials in patients with high-grade gliomas is exceedingly rare.

New technical solutions enable remote data collection, sharing data in real-time, notifications to health care team when needed, and integrating the results into the electronic health record. With the new technical solutions, the use of PROs may be a structured way to both measure, document, and communicate to improve the patient's health outcome and survivorship care. Today PRO measures, through a questionnaire, are often completed before an appointment with health care providers. More flexibility in the use of PRO measures might encourage patients to also report in-between visits, for example, patients or caregivers can document symptoms like side effects from treatment or seizures when it actually happens. However, to achieve clinical integration, first we need to find ways to share or visualize the results from PRO measures in a way patients, caregivers, and health care professionals can understand and respond to the results when needed.

\section{Conclusion}

Outcome measures are complex in patients with high-grade glioma. Efforts are being made with more refined and more holistic use of different COAs, including PRO measures in neuro-oncology. For clinical research, PRO measures need to be used together with other clinical outcome measures rather than replacing traditional outcome measures. Moving to more use of PRO measures in survivorship care has potential to improve patient-caregiver-health care team communication, symptom management, and quality of care. Implementing PROs in survivorship care should also involve caregivers and a routine to act on the results. We need to learn more about collecting and visualizing results and responding to PROs.

\section{Acknowledgment}

This project was funded by research grant from the Swedish Research Council (2017-00944).

\section{Disclosure}

The authors report no conflicts of interest in this work.

\section{References}

1. Louis DN, Perry A, Reifenberger G, et al. The 2016 World Health Organization classification of tumors of the central nervous system: a summary. Acta Neuropathol. 2016;131(6):803-820. doi:10.1007/ s00401-016-1545-1

2. Armstrong TS, Vera-Bolanos E, Acquaye AA, Gilbert MR, Ladha H, Mendoza T. The symptom burden of primary brain tumors: evidence for a core set of tumor- and treatment-related symptoms. Neuro-oncol. 2016;18(2):252-260. doi:10.1093/neuonc/nov166

3. Brandel MG, Alattar AA, Hirshman BR, et al. Survival trends of oligodendroglial tumor patients and associated clinical practice patterns: a SEER-based analysis. J Neurooncol. 2017;133(1):173-181. doi:10.1007/s11060-017-2430-z

4. Rusthoven CG, Carlson JA, Waxweiler TV, et al. The impact of adjuvant radiation therapy for high-grade gliomas by histology in the United States population. Int J Radiat Oncol Biol Phys. 2014;90 (4):894-902. doi:10.1016/j.ijrobp.2014.07.046

5. Smoll NR, Hamilton B. Incidence and relative survival of anaplastic astrocytomas. Neuro-oncol. 2014;16(10):1400-1407. doi:10.1093/ neuonc/nou053

6. Stupp R, Hegi ME, Mason WP, et al. Effects of radiotherapy with concomitant and adjuvant temozolomide versus radiotherapy alone on survival in glioblastoma in a randomised phase III study: 5-year analysis of the EORTC-NCIC trial. Lancet Oncol. 2009;10(5):459466. doi:10.1016/S1470-2045(09)70025-7

7. Weller M, van Den Bent M, Hopkins K, et al. EANO guideline for the diagnosis and treatment of anaplastic gliomas and glioblastoma. Lancet Oncol. 2014;15(9):e395-e403. doi:10.1016/S1470-2045(14) 70011-7

8. Dirven L, Aaronson NK, Heimans JJ, Taphoorn M. Health-related quality of life in high-grade glioma patients. Chin $J$ Cancer. 2014;33:40-45. doi:10.5732/cjc.013.10214

9. Dirven L, Armstrong TS, Blakeley JO, et al. Working plan for the use of patient-reported outcome measures in adults with brain tumours: a Response Assessment in Neuro-Oncology (RANO) initiative. Lancet Oncol. 2018;19(3):e173-e180. doi:10.1016/S1470-2045(18)30004-4 
10. Arpinelli F, Bamfi F. The FDA guidance for industry on PROs: the point of view of a pharmaceutical company. Health Qual Life Outcomes. 2006;4(1):85. doi:10.1186/1477-7525-4-85

11. Lovely MP, Stewart-Amidei C, Page M, et al. A new reality: longterm survivorship with a malignant brain tumor. Oncol Nurs Forum. 2013;40(3):267-274. doi:10.1188/13.ONF.267-274

12. Molassiotis A, Wilson B, Brunton L, Chaudhary H, Gattamaneni R, McBain C. Symptom experience in patients with primary brain tumours: a longitudinal exploratory study. Eur J Oncol Nurs. 2010;14(5):410-416. doi:10.1016/j.ejon.2010.03.001

13. Piil K, Juhler M, Jakobsen J, Jarden M. Daily life experiences of patients with a high-grade glioma and their caregivers: a longitudinal exploration of rehabilitation and supportive care needs. $J$ Neurosci Nurs. 2015;47(5):271-284. doi:10.1097/JNN.0000000000000158

14. Sherwood P, Hricik A, Donovan H, et al. Changes in caregiver perceptions over time in response to providing care for a loved one with a primary malignant brain tumor. Oncol Nurs Forum. 2011;38 (2):149-155. doi:10.1188/11.ONF.149-155

15. Sterckx W, Coolbrandt A, Dierckx de Casterle B, et al. The impact of a high-grade glioma on everyday life: a systematic review from the patient's and caregiver's perspective. Eur J Oncol Nurs. 2013;17 (1):107-117. doi:10.1016/j.ejon.2012.04.006

16. Leeper H, Milbury K. Survivorship care planning and implementation in neuro-oncology. Neuro-oncol. 2018;20(suppl7):vii40-vii46. doi:10.1093/neuonc/noy110

17. Westman B, Cornelius B. My cancer care plan as a web-solution. Stud Health Technol Inform. 2016;225:921-922.

18. Marzorati C, Riva S, Pravettoni G. Who is a cancer survivor? A systematic review of published definitions. J Cancer Educ. 2017;32 (2):228-237. doi:10.1007/s13187-016-0997-2

19. National Cancer Institute. NCI dictionary of cancer terms: symptom management. https://www.cancer.gov/publications/dictionaries/cancer-terms/def/symptom-management. Accessed July 03, 2019; 2019

20. Amidei C. Symptom-based interventions to promote quality survivorship. Neuro-oncol. 2018;20(supp17):vii27-vii39. doi:10.1093/neuonc/noy100

21. Beitz J, Gnecco C, Justice R. Quality-of-life end points in cancer clinical trials: the U.S. Food and Drug Administration perspective. $J$ Natl Cancer Inst Monogr. 1996;20:7-9.

22. Saxena S, Orley J. Quality of life assessment: the world health organization perspective. Eur Psychiatry. 1997;12(Supplement 3):263s-266s. doi:10.1016/S0924-9338(97)89095-5

23. Blakeley JO, Coons SJ, Corboy JR, Kline Leidy N, Mendoza TR, Wefel JS. Clinical outcome assessment in malignant glioma trials: measuring signs, symptoms, and functional limitations. Neuro-oncol. 2016;18 Suppl 2(Supp12):ii13-ii20. doi:10.1093/neuonc/nov291

24. Dirven L, Reijneveld JC, Taphoorn MJB. Health-related quality of life or quantity of life: a difficult trade-off in primary brain tumors? Semin Oncol. 2014;41(4):541-552. doi:10.1053/j.seminoncol.2014.06.002

25. Armstrong T, Mendoza T, Cohen M, Morrissey M, Gilbert M, Cleeland C. Reliability and validity of the M.D. Anderson symptom inventory (MDASI-BT) in the primary brain tumor patient population. Neuro-oncol. 2004;6(4):355-356.

26. Levin V, Phuphanich S, Alfred Yung WK, et al. Randomized, doubleblind, placebo-controlled trial of marimastat in glioblastoma multiforme patients following surgery and irradiation $\square$. J Neuro Oncol. 2006;78(3):295-302. doi:10.1007/s11060-005-9098-5

27. Reardon DA, Fink KL, Mikkelsen T, et al. Randomized phase II study of cilengitide, an integrin-targeting arginine-glycine-aspartic acid peptide, in recurrent glioblastoma multiforme. J Clin Oncol. 2008;26(34):5610. doi:10.1200/JCO.2007.15.2777

28. Roa W, Brasher P, Bauman G, et al. Abbreviated course of radiation therapy in older patients with glioblastoma multiforme: a prospective randomized clinical trial. J Clin Oncol. 2004;22(9):1583-1588. doi:10.1200/JCO.2004.06.082
29. Wick W, Puduvalli VK, Chamberlain MC, et al. Phase III study of enzastaurin compared with lomustine in the treatment of recurrent intracranial glioblastoma. $J$ Clin Oncol. 2010;28(7):1168. doi:10.1200/JCO.2009.23.2595

30. van Den Bent MJ, Carpentier AF, Brandes AA, et al. Adjuvant procarbazine, lomustine, and vincristine improves progression-free survival but not overall survival in newly diagnosed anaplastic oligodendrogliomas and oligoastrocytomas: a randomized european organisation for research and treatment of cancer phase III trial. J Clin Oncol. 2006;24(18):2715-2722. doi:10.1200/ JCO.2005.04.6078

31. Grabenbauer GG, Gerber K-D, Ganslandt O, et al. Effects of concurrent topotecan and radiation on 6-month progression-free survival in the primary treatment of glioblastoma multiforme. Int $J$ Radiat Oncol Biol Phys. 2009;75(1):164-169. doi:10.1016/j.ijrobp.2009.04.015

32. Henriksson R, Malmström A, Bergström P, et al. High-grade astrocytoma treated concomitantly with estramustine and radiotherapy. $J$ Neuro Oncol. 2006;78(3):321-326. doi:10.1007/s11060-005-9106-9

33. Keime-Guibert F, Chinot O, Taillandier L, et al. Radiotherapy for glioblastoma in the elderly. $N$ Engl J Med. 2007;356(15):1527-1535. doi:10.1056/NEJMoa065901

34. Kocher M, Frommolt P, Borberg SK, et al. Randomized study of postoperative radiotherapy and simultaneous temozolomide without adjuvant chemotherapy for glioblastoma. Strahlenther Onkol. 2008;184(11):572-579. doi:10.1007/s00066-008-1897-0

35. Malmström A, Grønberg BH, Marosi C, et al. Temozolomide versus standard 6-week radiotherapy versus hypofractionated radiotherapy in patients older than 60 years with glioblastoma: the nordic randomised, phase 3 trial. Lancet Oncol. 2012;13(9):916-926. doi:10.1016/ S1470-2045(12)70265-6

36. Stupp R, Mason WP, van Den Bent MJ, et al. Radiotherapy plus concomitant and adjuvant temozolomide for glioblastoma. $N$ Engl $J$ Med. 2005;352(10):987-996. doi:10.1056/NEJMoa043330

37. Stupp R, Wong ET, Kanner AA, et al. NovoTTF-100A versus physician's choice chemotherapy in recurrent glioblastoma: a randomised phase III trial of a novel treatment modality. Eur J Cancer. 2012;48 (14):2192-2202. doi:10.1016/j.ejca.2012.04.011

38. Wick W, Platten M, Meisner C, et al. Temozolomide chemotherapy alone versus radiotherapy alone for malignant astrocytoma in the elderly: the NOA-08 randomised, phase 3 trial. Lancet Oncol. 2012;13(7):707-715. doi:10.1016/S1470-2045(12)70164-X

39. Dirven L, Taphoorn MJB, Reijneveld JC, et al. The level of patientreported outcome reporting in randomised controlled trials of brain tumour patients: a systematic review. Eur J Cancer. 2014;50 (14):2432-2448. doi:10.1016/j.ejca.2014.06.016

40. Brundage M, Blazeby J, Revicki D, et al. Patient-reported outcomes in randomized clinical trials: development of ISOQOL reporting standards. Qual Life Res. 2013;22(6):1161-1175. doi:10.1007/ s11136-012-0252-1

41. Calvert M, Blazeby J, Altman DG, Revicki DA, Moher D, Brundage MD. Reporting of patient-reported outcomes in randomized trials: the CONSORT PRO extension. JAMA. 2013;309 (8):814-822. doi:10.1001/jama.2013.879

42. Taphoorn MJB, Dirven L, Kanner AA, et al. Influence of treatment with tumor-treating fields on health-related quality of life of patients with newly diagnosed glioblastoma: a secondary analysis of a randomized clinical trialtreatment with tumor-treating fields in patients with glioblastomatreatment with tumor-treating fields in patients with glioblastoma. JAMA Oncol. 2018;4(4):495-504. doi:10.1001/ jamaoncol.2017.5082

43. Dirven LJ, van Den Bent M, Bottomley A, et al. The Impact of Bevacizumab on Health-related Quality of Life in Patients Treated for Recurrent Glioblastoma: Results of the Randomised Controlled Phase 2 BELOB Trial. Eur J Cancer. 2015;51(10):1321-30. 
44. Dirven L, Reijneveld J, Aaronson N, Bottomley A, Uitdehaag B, Taphoorn M. Health-related quality of life in patients with brain tumors: limitations and additional outcome measures. Curr Neurol Neurosci Rep. 2013;13(7):1-9. doi:10.1007/s11910-013-0359-y

45. Dirven L, Armstrong TS, Taphoorn MJB. Health-related quality of life and other clinical outcome assessments in brain tumor patients: challenges in the design, conduct and interpretation of clinical trials. Neuro Oncol Pract. 2015;2(1):2-5. doi:10.1093/nop/npv002

46. Roydhouse JK, Wilson IB. Systematic review of caregiver responses for patient health-related quality of life in adult cancer care. Qual Life Res. 2017;26(8):1925-1954. doi:10.1007/s11136-017-1540-6

47. Giesinger JM, Golser M, Erharter A, et al. Do neurooncological patients and their significant others agree on quality of life ratings? Health Qual Life Outcomes. 2009;7:87. doi:10.1186/1477-7525-7-87

48. Sneeuw KC, Aaronson NK, Osoba D, et al. The use of significant others as proxy raters of the quality of life of patients with brain cancer. Med Care. 1997;35(5):490-506.

49. Brown DP, Decker AP, Rummans AT, et al. A prospective study of quality of life in adults with newly diagnosed high-grade gliomas: comparison of patient and caregiver ratings of quality of life. Am J Clin Oncol. 2008;31 (2):163-168. doi:10.1097/COC.0b013e318149f1d3

50. Jacobs DI, Kumthekar P, Stell BV, et al. Concordance of patient and caregiver reports in evaluating quality of life in patients with malignant gliomas and an assessment of caregiver burden. Neuro Oncol Pract. 2014;1(2):47-54. doi:10.1093/nop/npu004

51. Stell B, Jacobs D, Grimm SA, et al. Quality-of-life concordance between patients with malignant gliomas and their caregivers: updated data. J Clin Oncol. 2011;29(15):9053. doi:10.1200/ jco.2011.29.15_suppl.9053

52. Armstrong TS, Wefel JS, Gning I, et al. Congruence of primary brain tumor patient and caregiver symptom report. Cancer $(0008543 X)$. 2012;118(20):5026. doi:10.1002/cncr.27483

53. Gning I, Armstrong T, Wefel J, et al. ASSESSING THE VALIDITY OF THE MD ANDERSON SYMPTOM INVENTORY-BRAIN TUMOR (MDASI-BT) USING CAREGIVER PROXY REPORT. Neuro-oncol. 2012;14(s6):158.

54. Fox P, Furlong E, Buick A, et al. The eSMART Project: Real-time Symptom Management in the Irish Oncology Setting. Cancer Professional, Summer, 2016:22-24.

55. Snyder FC, Jensen ER, Segal BJ, Wu WA. Patient-reported outcomes (PROs): putting the patient perspective in patient-centered outcomes research. Med Care. 2013;51 Suppl(8 Suppl 3), Electronic Data Methods (EDM) Forum Special Supplement(8 Suppl 3):S73-S79. doi:10.1097/MLR.0b013e31829b1d84

56. Basch E, Deal AM, Kris MG, et al. Symptom monitoring with patient-reported outcomes during routine cancer treatment: a randomized controlled trial. J Clin Oncol. 2015;34(6):557-565. doi:10.1200/JCO.2015.63.0830

57. Denis F, Lethrosne C, Pourel N, et al. Randomized trial comparing a web-mediated follow-up with routine surveillance in lung cancer patients. J Natl Cancer Inst. 2017;109(9):djx029. doi:10.1093/jnci/ djx029

58. Basch E, Abernethy AP. Supporting clinical practice decisions with real-time patient-reported outcomes. J Clin Oncol. 2011;29(8):954 956. doi:10.1200/JCO.2010.33.2668

59. Basch E, Spertus J, Adams Dudley R, et al. Methods for developing patient-reported outcome-based performance measures (PRO-PMs). Value Health. 2015;18(4):493-504. doi:10.1016/j.jval.2015.02.018

60. Blackford AL, Wu AW, Snyder C. Interpreting and acting on PRO results in clinical practice: lessons learned from the patientviewpoint system and beyond. Med Care. 2019;57 Suppl 5(Suppl 1):S46-S51. doi:10.1097/MLR.0000000000001086

61. Loth F, Holzner B, Sztankay M, et al. Cancer patients' understanding of longitudinal EORTC QLQ-C30 scores presented as bar charts. Patient Educ Couns. 2016;99(12):2012-2017. doi:10.1016/j. pec.2016.08.004
62. Bantug ET, Coles T, Smith KC, Snyder CF, Rouette J, Brundage MD. Graphical displays of patient-reported outcomes (PRO) for use in clinical practice: what makes a pro picture worth a thousand words? Patient Educ Couns. 2016;99(4):483-490. doi:10.1016/j. pec.2015.10.027

63. Snyder CF, Blackford AL, Okuyama T, et al. Using the EORTCQLQ-C30 in clinical practice for patient management: identifying scores requiring a clinician's attention. Qual Life Res. 2013;22 (10):2685. doi:10.1007/s11136-012-0169-8

64. Snyder CF, Blackford AL, Sussman J, et al. Identifying changes in scores on the EORTC-QLQ-C30 representing a change in patients' supportive care needs. Qual Life Res. 2015;24(5):1207-1216. doi:10.1007/s11136-014-0853-y

65. Wintner LM, Sztankay M, Aaronson N, et al. The use of EORTC measures in daily clinical practice-A synopsis of a newly developed manual. Eur J Cancer. 2016;68:73-81. doi:10.1016/j.ejca.2016.08.024

66. King S, Exley J, Parks S, et al. The use and impact of quality of life assessment tools in clinical care settings for cancer patients, with a particular emphasis on brain cancer: insights from a systematic review and stakeholder consultations. Qual Life Res. 2016;25 (9):2245-2256. doi:10.1007/s11136-016-1278-6

67. Armstrong TS, Mendoza T, Gning I, et al. Validation of the M.D. Anderson Symptom Inventory Brain Tumor Module (MDASI-BT). $J$ Neuro Oncol. 2006;80(1):27-35. doi:10.1007/s11060-006-9135-Z

68. Armstrong TS, Cohen MZ, Eriksen LR, Hickey JV. Symptom clusters in oncology patients and implications for symptom research in people with primary brain tumors. J Nurs Scholarsh. 2004;36(3):197-206.

69. Armstrong TS, Cron SG, Bolanos EV, Gilbert MR, Kang DH. Risk factors for fatigue severity in primary brain tumor patients. Cancer. 2010;116(11):2707-2715. doi:10.1002/cncr.25018

70. Armstrong TS, Vera-Bolanos E, Gning I, et al. The impact of symptom interference using the MD Anderson Symptom Inventory-Brain Tumor Module (MDASI-BT) on prediction of recurrence in primary brain tumor patients. Cancer. 2011;117(14):3222-3228. doi:10.1002/ cncr.25892

71. Lai JS, Jensen SE, Beaumont JL, et al. Development of a symptom index for patients with primary brain tumors. Value Health. 2014;17 (1):62-69. doi:10.1016/j.jval.2013.11.006

72. Rooney A, Netten A, McNamara S, et al. Assessment of a braintumour-specific patient concerns inventory in the neuro-oncology clinic. Support Care Cancer. 2014;22(4):1059-1069. doi:10.1007/ s00520-013-2058-2

73. Young J, Cund A, Renshaw M, Quigley A, Snowden A. Improving the Care of Cancer Patients: Holistic Needs Assessment. Br J Nurs. 2015;24(4):S17-20. doi:10.12968/bjon.2015.24.Sup4.S17

74. Liu F, Huang J, Zhang L, et al. Screening for distress in patients with primary brain tumor using distress thermometer: a systematic review and meta-analysis. BMC Cancer. 2018;18(1):124. doi:10.1186/s12885-0184242-8

75. Trad W, Koh E-S, Daher M, et al. Screening for Psychological Distress in Adult Primary Brain Tumor Patients and Caregivers: Considerations for Cancer Care Coordination. Front Oncol. 2015;5:203. doi:10.3389/ fonc. 2015.00203

76. Armstrong TS, Cohen MZ, Eriksen L, Cleeland C. Content validity of self-report measurement instruments: an illustration from the development of the brain tumor module of the M.D. Anderson symptom inventory. Oncol Nurs Forum. 2005;32(3):669-676. doi:10.1188/05.ONF.669-676

77. Afseth J, Neubeck L, Karatzias T, Grant R. Holistic needs assessment in brain cancer patients: a systematic review of available tools. Neurooncol 2018;20(supp11):i12-i12. doi:10.1093/neuonc/nox238.051

78. Chang JH, Kim C-Y, Choi BS, Kim YJ, Kim JS, Kim IA. Pseudoprogression and pseudoresponse in the management of highgrade glioma: optimal decision timing according to the response assessment of the neuro-oncology working group. $J$ Korean Neurosurg Soc. 2014;55(1):5-11. doi:10.3340/jkns.2014.55.1.5 
79. Armstrong T, Gilbert M. Patient reported endpoints for measuring clinical benefit in (High grade glioma) primary brain tumor patients. Curr Treat Options Oncol. 2014;15(4):519-528. doi:10.1007/s11864014-0302-8

80. Wen PY, Chang SM, Van Den Bent MJ, Vogelbaum MA, Macdonald DR, Lee EQ. Response assessment in neuro-oncology clinical trials. $J$ Clin Oncol. 2017;35(21):2439. doi:10.1200/JCO.2017.72.7511

81. Armstrong TS, Wefel JS, Wang M, et al. Clinical utility of neurocognitive function (NCF), quality of life (QOL), and symptom assessment as prognostic factors for survival and measures of treatment effects on RTOG 0525. J Clin Oncol. 2011;29(15_suppl):2016. doi:10.1200/jco.2011.29.15_suppl.2016

82. Nayak L, DeAngelis LM, Brandes AA, et al. The Neurologic Assessment in Neuro-Oncology (NANO) scale: a tool to assess neurologic function for integration into the Response Assessment in Neuro-Oncology (RANO) criteria. Neuro-oncol 2017;19(5):625-635. doi:10.1093/ neuonc/nox029

83. Oort Q, Dirven L, Meijer W, et al. Development of a questionnaire measuring instrumental activities of daily living (IADL) in patients with brain tumors: a pilot study. J Neuro Oncol. 2017;132(1):145153. doi:10.1007/s11060-016-2352-1

84. Oort Q, Taphoorn MJB, Sikkes SAM, Uitdehaag BMJ, Reijneveld JC, Dirven L. Evaluation of the content coverage of questionnaires containing basic and instrumental activities of daily living (ADL) used in adult patients with brain tumors. J Neuro Oncol. 2019;143 (1):1-13. doi:10.1007/s11060-019-03136-9

85. van Leeuwen $\mathrm{M}$, Husson $\mathrm{O}$, Alberti $\mathrm{P}$, et al. Understanding the quality of life (QOL) issues in survivors of cancer: towards the development of an EORTC QOL cancer survivorship questionnaire. Health Qual Life Outcomes. 2018;16(1):114. doi:10.1186/s12955018-0920-0

86. Petersen MA, Aaronson NK, Arraras JI, et al. The EORTC CAT Core-The computer adaptive version of the EORTC QLQ-C30 questionnaire. Eur J Cancer. 2018;100:8-16. doi:10.1016/j. ejca.2018.04.016

87. Wagner LI, Schink J, Bass M, et al. Bringing PROMIS to practice: brief and precise symptom screening in ambulatory cancer care. Cancer. 2015;121(6):927-934. doi:10.1002/cncr.29104

88. Gabel N, Altshuler DB, Brezzell A, et al. Health related quality of life in adult low and high-grade glioma patients using the national institutes of health Patient Reported Outcomes Measurement Information System (PROMIS) and Neuro-QOL Assessments. Front Neurol. 2019;10:212. doi:10.3389/fneur.2019.00212
89. Drewes C, Sagberg LM, Jakola AS, Gulati S, Solheim O. Morbidity after intracranial tumor surgery: sensitivity and specificity of retrospective review of medical records compared with patient-reported outcomes at 30 days. $J$ Neurosurg. 2015;123(4):972-977. doi: $10.3171 / 2014.12 . J N S 142206$

90. Ediebah DE, Reijneveld JC, Taphoorn MJB, et al. Impact of neurocognitive deficits on patient-proxy agreement regarding healthrelated quality of life in low-grade glioma patients. Qual Life Res. 2017;26(4):869-880. doi:10.1007/s11136-016-1426-z

91. Aaronson NK, Ahmedzai S, Bergman B, et al. The European Organization for Research and Treatment of Cancer QLQ-C30: a quality-of-life instrument for use in international clinical trials in oncology. $J$ Natl Cancer Inst. 1993;85(5):365-376. doi:10.1093/jnci/85.5.365

92. Taphoorn MJ, Claassens L, Aaronson NK, et al. An international validation study of the EORTC brain cancer module (EORTC QLQBN20) for assessing health-related quality of life and symptoms in brain cancer patients. Eur J Cancer. 2010;46(6):1033-1040. doi:10.1016/j.ejca.2010.01.012

93. Cella DF, Tulsky DS, Gray G, et al. The functional assessment of cancer therapy scale: development and validation of the general measure. J Clin Oncol. 1993;11(3):570. doi:10.1200/JCO.1993.11.12.2411

94. Osoba D, Aaronson NK, Muller M, et al. The development and psychometric validation of a brain cancer quality-of-life questionnaire for use in combination with general cancer-specific questionnaires. Qual Life Res. 1996;5(1):139-150.

95. Weitzner M, Meyers C, Gelke C, Byrne K, Cella D, Levin V. The Functional Assessment of Cancer Therapy (FACT) Scale Development of a brain subscale and revalidation of the general version (FACT-G) in patients with primary brain tumors. Cancer. 1995;75 (5):1151-1161. doi:10.1002/1097-0142(19950301)75:5<1151::aidcncr2820750515>3.0.co;2-q

96. Armstrong TS. Development and Validation of the Neuro Symptom Inventory in the Primary Brain Tumor Patient Population. Texas Medical Center Dissertations (via ProQuest). AAI3198902. University of Texas School of Nursing at Houston; 2005.

97. Bonevski B, Sanson-Fisher R, Girgis A, Burton L, Cook P, Boyes A. Evaluation of an instrument to assess the needs of patients with cancer. (Supportive Care Review Group). Cancer. 2000;88(1):217. doi:10.1002/(SICI)1097-0142(20000101)88:1<217::AIDCNCR29>3.0.CO;2-Y

98. Janda M, Steginga S, Dunn J, Langbecker D, Walker D, Eakin E. Unmet supportive care needs and interest in services among patients with a brain tumour and their carers. Patient Educ Couns. 2008;71 (2):251-258. doi:10.1016/j.pec.2008.01.020
Patient Related Outcome Measures

\section{Publish your work in this journal}

Patient Related Outcome Measures is an international, peer-reviewed, open access journal focusing on treatment outcomes specifically relevant to patients. All aspects of patient care are addressed within the journal and practitioners from all disciplines are invited to submit their work as well as healthcare researchers and patient support groups.
The manuscript management system is completely online and includes a very quick and fair peer-review system. Visit http://www. dovepress.com/testimonials.php to read real quotes from published authors. 